\title{
The association between ambient air pollution and scarlet fever in Qingdao, China, 2014-2018: a quantitative analysis
}

Fachun Jiang ${ }^{1 \dagger}$, $\mathrm{Tao} \mathrm{Wei}^{2 \dagger}$, Xiaowen $\mathrm{Hu}^{1 \dagger}$, Yalin Han ${ }^{1}$, Jing Jia ${ }^{1}$, Bei Pan ${ }^{1}$ and Wei $\mathrm{Ni}^{2^{*}}$

\begin{abstract}
Background: We conducted a distributed lag non-linear time series analysis to quantify the association between air pollution and scarlet fever in Qingdao city during 2014-2018.

Methods: A distributed lag non-linear model (DLNM) combined with a generalized additive mixed model (GAMM) was applied to quantify the distributed lag effects of air pollutions on scarlet fever, with daily incidence of scarlet fever as the dependent variable and air pollutions as the independent variable adjusted for potential confounders.

Results: A total of 6316 cases of scarlet fever were notified, and there were 376 days occurring air pollution during the study period. Scarlet fever was significantly associated with air pollutions at a lag of 7 days with different relative risk (RR) of air pollution degrees [1.172, 95\% confidence interval (Cl): 1.038-1.323 in mild air pollution; $1.374,95 \% \mathrm{Cl}$ $1.078-1.749$ in moderate air pollution; $1.610,95 \% \mathrm{Cl} 1.163-2.314$ in severe air pollution; $1.887,95 \% \mathrm{Cl} 1.163-3.061$ in most severe air pollution].

Conclusions: Our findings show that air pollution is positively associated with scarlet fever in Qingdao, and the risk of scarlet fever could be increased along with the degrees of air pollution. It contributes to developing strategies to prevent and reduce health impact from scarlet fever and other non-vaccine-preventable respiratory infectious diseases in air polluted areas.
\end{abstract}

Keywords: Air pollution, Scarlet fever, Relative risk, Distributed lag non-linear model

\section{Background}

Scarlet fever is an infectious disease caused by toxinproducing strains of the bacteria Streptococcus pyogenes (Group A Streptococcus, GAS), which occurs most commonly in association with pharyngitis [1, 2]. Although the effective antibiotics, hygiene and nutrition have been improved in the past decade, the re-emergency of scarlet fever was noted in some areas over the globe, such

\footnotetext{
*Correspondence: 115438779@qq.com

${ }^{\dagger}$ Fachun Jiang, Tao Wei and Xiaowen Hu are co-first authors

${ }^{2}$ Qingdao Women and Children's Hospital, Qingdao University, No.6

Tongfu Road, Qingdao City 266000, Shandong Province, People's

Republic of China

Full list of author information is available at the end of the article
}

as South Korea, Vietnam England, UK as well as China [3-9]. Notably, among the areas, China is facing an increasing threat of scarlet fever after implementation of two-child policy from 2011, which had a significant increase in the reports of scarlet fever. Yet, the reason for this increase has been not clear, which is suggested with potential association between microbial, host, meteorological and environmental factors [10]. Due to the rapid economic development and urbanization in China, the frequency and severity of air pollution episodes increased over the last two decades, resulting in a risk of health impacts on an unprecedented scale [11-16]. The emerging cases of scarlet fever and worsening air pollution 
may suggest a potential linkage, however, few evidence revealed this association in a large population study.

In eastern China, more air pollution events were observed compared with other areas [17]. Qingdao, as an important economic center and a seaport in eastern China, has suffered from air pollution frequently, which is presented as a region with high $\mathrm{PM}_{2.5}$ and $\mathrm{PM}_{10}$ mass concentrations [18]. What happening with worsening air pollution at the same time is the increasing incidence of scarlet fever, which is a significant threat to the growing child population in Qingdao [19]. Therefore, Qingdao, presented as the site, is appropriate to explore the association between air pollution and scarlet fever. At present, we conducted a distributed lag non-linear time series analysis to quantify the association between them in a large population study in Qingdao, China during 20142018, aiming at providing facility to developing strategies for preventing and reducing health impact from scarlet fever and other non-vaccine-preventable respiratory infectious diseases in air polluted areas.

\section{Methods}

\section{Study site}

As shown in Fig. 1, Qingdao is a coastal city of Shandong province, which is situated in eastern China between longitude $119^{\circ} 30^{\prime}-121^{\circ} 00^{\prime} \mathrm{E}$ and latitude $35^{\circ} 35^{\prime}-37^{\circ} 09^{\prime} \mathrm{N}$. The city has a mid-temperate continental monsoon climate with an annual average of $12.7^{\circ} \mathrm{C}$ and annual cumulative precipitation of $662.1 \mathrm{~mm}$. Additionally, as a harbor city, Qingdao is the economic center of Shandong province with a population density of 801 persons per $\mathrm{km}^{2}$ (in 2014: population $=9,046,200$; land size $=11,282 \mathrm{~km}^{2}$ ).

\section{Data collection and management Data on disease}

Resource and collection of disease data was depicted in the previous article written by Rao et al. [20]. Daily data on scarlet fever from 2014 to 2018 in Qingdao were obtained from the Notifiable Disease Surveillance System (NDSS). According to the Chinese Infectious Diseases Law, clinicians must report to the NDSS when they identify any probable, clinical, or laboratory-confirmed case of scarlet fever within $24 \mathrm{~h}$ of diagnosis, and it ensures that the morbidity of scarlet fever is a relative real figure of the city. Additionally, all cases of scarlet fever were diagnosed according to the diagnostic criteria for scarlet fever issued by the Ministry of Health of the People's Republic of China in 2008 [21]. This study was approved by the Ethics Commission of Qingdao Municipal Center for Disease Control and Prevention (Date: 18 Oct, 2019; Number: QFELL-KY-2019-67).

\section{Air pollution data}

Resource and collection of air pollution data was depicted in the previous article [22]. Air pollution data during 2014-2018 in Qingdao were obtained from China National Environmental Monitoring Center, including data of daily air quality index and air pollutant concentrations, such as $\mathrm{PM}_{2.5}, \mathrm{PM}_{10}$, sulfur dioxide $\left(\mathrm{SO}_{2}\right)$, carbon monoxide $(\mathrm{CO})$, nitrogen dioxide $\left(\mathrm{NO}_{2}\right)$ and ozone $\left(\mathrm{O}_{3}\right)$. According to Ambient Air Quality Standards issued by Ministry of Ecology and Environment of the People's Republic of China in December 2012, the standard limits of particulate matter with a diameter less 2.5 microns $\left(\mathrm{PM}_{2.5}\right)$, particulate matter with a diameter less 10 microns $\left(\mathrm{PM}_{10}\right), \mathrm{SO}_{2}, \mathrm{CO}$ and

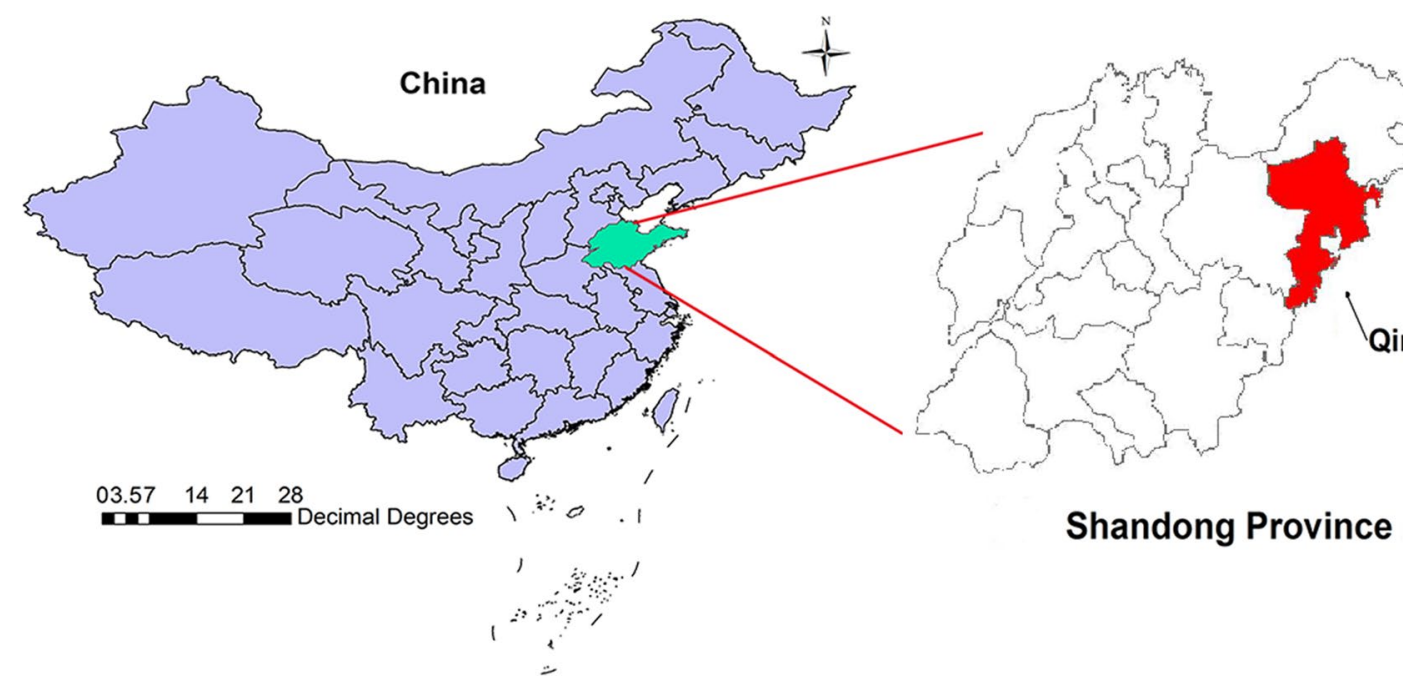

Fig. 1 Location of Qingdao in Shandong Province, China (the image depicted in Fig. 1 is our own) 
$\mathrm{NO}_{2}$ concentrations, equivalently to the 24-h means, are $75 \mu \mathrm{g} / \mathrm{m}^{3}, 150 \mu \mathrm{g} / \mathrm{m}^{3}, 150 \mu \mathrm{g} / \mathrm{m}^{3}, 4 \mathrm{mg} / \mathrm{m}^{3}$ and $80 \mu \mathrm{g} / \mathrm{m}^{3}$, respectively, followed by the $\mathrm{O}_{3}$ concentration limit with $200 \mu \mathrm{g} / \mathrm{m}^{3}$ on eight hours average [22].

The previous article introduced the definition of air pollution and its assessment process in detail, which was also applied in this study [22]. Air pollution is defined as the phenomenon or event that the content of any substance in atmospheric are varied harmfully for ecological stability and the condition of human survival, causing hazards for human, animals, vegetation or material [22]. Severity of air pollution is indicated by different air quality index (AQI) value ranges. AQI is a number used by government agencies to communicate to the public how polluted the air is currently, which is summarized by considering several main air pollutants and calculated by Individual Air Quality Index (IAQI) of each pollutant [22]. IAQI represents the state of individual contaminant. The IAQI was calculated as follows according to the Technical Regulation on Ambient Air Quality Index (on trial):

$$
I A Q I_{P}=\frac{I A Q I_{H i}-I A Q I_{L o}}{B P_{H i}-B P_{L o}}\left(C_{P}-B P_{L o}\right)+I A Q I_{L o}
$$

$\mathrm{IAQI}_{\mathrm{P}}$ represents the Individual Air Quality Index of $P$ contaminant. $C_{p}$ represents the mass concentration of $\mathrm{P}$ contaminant. $\mathrm{BP}_{\mathrm{Hi}}$ and $\mathrm{BP}_{\mathrm{Lo}}$ represent the highest and lowest value of concentration limit like $C_{P}$, respectively. $\mathrm{IAQI}_{\mathrm{Hi}}$ and $\mathrm{IAQI}_{\mathrm{Lo}}$ represent the Individual Air Quality Index of $\mathrm{BP}_{\mathrm{Hi}}$ and $\mathrm{BP}_{\mathrm{Lo}}$, respectively [22].

The AQI was calculated as followed:

$$
A Q I=\max \left\{\mathrm{IAQI}_{1}, \mathrm{IAQI}_{2}, \mathrm{IAQI}_{3}, \ldots, \mathrm{IAQI}_{\mathrm{n}}\right\}
$$

IAQI represents the Individual Air Quality Index of contaminants. $\mathrm{n}$ represents the specific contaminant.

AQI values are divided into four ranges, and each range is assigned a descriptor for air pollution level. According to the Technical Regulation on Ambient Air Quality Index (on trial), air pollution is divided into 4 levels on the basis of AQI value, including mild pollution (AQI: 101-150), moderate pollution (AQI: 151200), severe pollution (AQI: 201-300) and most severe pollution (AQI: > 300) [22].

\section{Meteorological data}

Meteorological data from 2014 to 2018 were collected from the China Meteorological Data Sharing Service System (http://cdc.cma.gov.cn/), which includes daily data such as daily cumulative precipitation, daily mean temperature and daily mean air pressure.

\section{Statistical analysis}

First, the distribution of scarlet fever morbidity and air pollution variables were described during the study period. Second, a distributed lag non-linear model (DLNM) combined with a generalized additive mixed model (GAMM) was applied to quantify the distributed lag effects of air pollutions on scarlet fever, with daily morbidity of scarlet fever as the dependent variable and air pollutions as the independent variable adjusted for potential confounders. A quasi-Poisson regression was used to deal with the over dispersion of Poisson distribution. In order to control the potential confounds, factors including meteorological factors, long-term and seasonal trend, day of the week and public holidays were introduced into the model simultaneously. The model is as follows:

$$
\begin{aligned}
\log \left[E\left(Y_{t}\right)\right]= & \alpha+\sum_{p=0}^{7} \beta_{p}\left({\text { Air } \left.\text { Pollution }_{t-p}, D F\right)}^{7}\right. \\
& +\sum_{q=0}^{7} \beta_{q}\left(\text { Air } \text { Pollutant }_{t-q}, D F\right) \\
& +N S_{1}(\text { Prec }, D F)+N S_{2}(\text { Temp }, D F) \\
& +N S_{3}(\text { Pressure }, D F) \\
& +N S_{4}(\text { Time }, D F)+D O W_{t}+\text { Holiday }
\end{aligned}
$$

$\mathrm{Y}_{\mathrm{t}}$ denoted the daily morbidity of scarlet fever on day $\mathrm{t}$. $\alpha$ was the intercept. Air Pollution was a categorical variable including non-air pollution, mild air pollution, moderate air pollution, severe air pollution or most severe air pollution, represented by $0,1,2,3$ and 4 , respectively. The $\beta_{\mathrm{p}}$ was the effect estimate of the air pollution $\mathrm{p}$ days before the day of illness. Air Pollutant was a metric variable presenting the concentration of air pollutant. The $\beta_{\mathrm{q}}$ was the effect estimate of a 10-unit of increase of air pollutant concentration (with reference to its standard limit) $\mathrm{q}$ days before the day of illness. The $\mathrm{NS}_{1}$ (Prec, DF), $\mathrm{NS}_{2}$ (Temp, DF), $\mathrm{NS}_{3}$ (Pressure, DF) and $\mathrm{NS}_{4}$ (Time, DF) were natural cubic splines of daily cumulative precipitation, daily mean temperature, daily mean air pressure and time [as the number of days $(1,2,3 \ldots 1086)]$, respectively, which were designed to control the effects of meteorological factors, long-term trend and seasonality. DF was the degree of freedom. $\mathrm{DOW}_{\mathrm{t}}$ was the day of the week on day $\mathrm{t}$, which was a categorical variable $(1,2,3 \ldots 7)$. Holiday was a binary variable including public holiday or workday, represented by 1 and 0 .

All degrees of freedom of variables were selected according to the empirical researches. In order to completely capture the effects of air pollution and air pollutant concentrations on daily morbidity of scarlet fever, the DLNM was applied for air pollution and air pollutants in 
our study with both 3 degrees of freedom (DF) [23-25]. Using a natural cubic spline, we chose DF as 7 per year for Time to remove long term trends and seasonality impact [25]. Additionally, we used smooth function of natural cubic splines with 3 DF in the model for daily cumulative precipitation, daily mean temperature and daily mean air pressure [26, 27]. Previous studies have shown that the lagged effect of air pollutants on respiratory diseases were usually short $[28,29]$. The incubation period of scarlet fever is usually between 1 and 3 days [30]. However, considering the delayed environmental transport of pathogens and delayed onset of clinical symptoms, morbidity of scarlet fever was expected to peak several days after the exposure of air pollution. Therefore, a lag effect at a maximum of 7 days was applied in the DLNM.

Air pollutants usually have a highly interaction effect, which may result in collinearity in the model. In order to avoid the collinearity, the pairwise correlation was applied by spearman correlation analysis in all air pollutants. As shown in Additional file 1: Table S1, there were two pairs with no significant correlation among the six air pollutants, including $\mathrm{PM}_{2.5}-\mathrm{O}_{3}(\mathrm{r}=-0.025, \mathrm{P}<0.05)$ and $\mathrm{PM}_{10}-\mathrm{O}_{3}(\mathrm{r}=0.006, \mathrm{P}<0.05)$. Previous studies found the strong association between $\mathrm{PM}_{2.5}, \mathrm{O}_{3}$ and respiratory infectious disease [31, 32], thus, our study focused on
$\mathrm{PM}_{2.5}$ and $\mathrm{O}_{3}$ as the pollutant variables included in the model to assess their impact.

In order to detect the potential autoregressive correlation of the model, the Durbin-Watson (D-W) test was conducted, and results showed that D-W statistic was 1.84 with the $\mathrm{P}$ value of 0.16 , revealing that the model with no autoregressive correlation.

Sensitive analysis was performed by altering DF (6-9 per year) for Time, and DF (2-5) for daily cumulative precipitation, daily mean temperature and daily air pressure. $\mathrm{R}$ software (version 3.2.2, R Development Core Team 2015) was used to perform all statistical analyses. The "dlnm" package was used to create the DLNM model. All statistical tests were two-sided, and $P$ values with less than 0.05 were considered statistically significant.

\section{Results}

\section{Description of disease and air pollution}

A total of 6316 cases of scarlet fever were notified in the study area over no air pollution and air pollution periods from 2014 to 2018. Descriptive statistics of the scarlet fever morbidity, air pollution and meteorological factors were presented in Table 1 , which were significantly different between non-air pollution and air pollution periods.

Table 1 Description of scarlet fever incidence, air pollution and meteorological factors from 2014 to 2018 in Qingdao city

\begin{tabular}{|c|c|c|c|c|c|c|c|}
\hline Variables & Period & Mean \pm SD & Min & $P_{25}$ & Median & $P_{75}$ & Max \\
\hline \multirow[t]{2}{*}{ Daily morbidity of scarlet fever $\left(1 \times 10^{8}\right)$} & No air pollution period & $3.7 \pm 3.7$ & 0 & 1.1 & 2.2 & 5.4 & 23.9 \\
\hline & Air pollution period* & $4.3 \pm 4.2$ & 0 & 1.1 & 3.3 & 6.5 & 22.6 \\
\hline \multirow[t]{2}{*}{$\mathrm{PM}_{2.5}\left(\mu \mathrm{g} / \mathrm{m}^{3}\right)$} & No air pollution period & $32.6 \pm 16.9$ & 0 & 19.8 & 29.0 & 43.0 & 95.0 \\
\hline & Air pollution period* & $89.0 \pm 44.5$ & 0 & 58.0 & 83.5 & 107.0 & 304.0 \\
\hline \multirow[t]{2}{*}{$\mathrm{PM}_{10}\left(\mu \mathrm{g} / \mathrm{m}^{3}\right)$} & No air pollution period & $70.0 \pm 66.0$ & 0 & 48.0 & 66.0 & 90.0 & 165.0 \\
\hline & Air pollution period* & $156.0 \pm 63.1$ & 0 & 119.0 & 150.0 & 186.0 & 455.0 \\
\hline \multirow[t]{2}{*}{$\mathrm{SO}_{2}\left(\mu \mathrm{g} / \mathrm{m}^{3}\right)$} & No air pollution period & $17.9 \pm 12.4$ & 2.0 & 9.0 & 15.5 & 23.0 & 79.0 \\
\hline & Air pollution period* & $33.8 \pm 22.2$ & 2.0 & 18.0 & 28.0 & 43.0 & 132.0 \\
\hline \multirow[t]{2}{*}{$\mathrm{CO}\left(\mathrm{mg} / \mathrm{m}^{3}\right)$} & No air pollution period & $0.7 \pm 0.6$ & 0.2 & 0.5 & 0.6 & 0.8 & 8.6 \\
\hline & Air pollution period* & $1.3 \pm 0.8$ & 0.4 & 0.9 & 1.1 & 1.5 & 12.6 \\
\hline \multirow[t]{2}{*}{$\mathrm{NO}_{2}\left(\mu \mathrm{g} / \mathrm{m}^{3}\right)$} & No air pollution period & $31.9 \pm 14.4$ & 3.0 & 21.0 & 30.0 & 40.0 & 107.0 \\
\hline & Air pollution period* & $48.7 \pm 18.9$ & 9.0 & 34.0 & 46.0 & 62.8 & 111.0 \\
\hline \multirow[t]{2}{*}{$\mathrm{O}_{3}\left(\mu \mathrm{g} / \mathrm{m}^{3}\right)$} & No air pollution period & $94.5 \pm 32.2$ & 0 & 68.0 & 95.0 & 119.0 & 161.0 \\
\hline & Air pollution period* & $113.0 \pm 60.7$ & 0 & 58.3 & 99.0 & 168.8 & 254.0 \\
\hline \multirow[t]{2}{*}{ Cumulative precipitation (mm) } & No air pollution period & $1.9 \pm 7.7$ & 0 & 0 & 0 & 0 & 121.4 \\
\hline & Air pollution period* & $0.3 \pm 2.6$ & 0 & 0 & 0 & 0 & 39.2 \\
\hline \multirow[t]{2}{*}{ Average temperature $\left({ }^{\circ} \mathrm{C}\right)$} & No air pollution period & $14.3 \pm 9.6$ & -12.9 & 6.4 & 15.7 & 22.6 & 30.5 \\
\hline & Air pollution period* & $11.9 \pm 9.4$ & -4.4 & 3.7 & 9.9 & 20.1 & 30.6 \\
\hline \multirow[t]{2}{*}{ Average air pressure (KPa) } & No air pollution period & $1000.8 \pm 9.2$ & 988.3 & 1000.4 & 1008.4 & 1015.8 & 1032.3 \\
\hline & Air pollution period* & $1009.3 \pm 8.7$ & 987.8 & 1001.9 & 1010.4 & 1016.0 & 1027.6 \\
\hline
\end{tabular}

SD standard deviation, Min minimum, $P 25$ the 25 th percentile, $P 75$ the 75 th percentile, Max maximum

*P $<0.05$ vs. non-flooded month 
During the study period, there were 376 days occurring air pollution, including 278 days with mild air pollution, 58 days with moderate air pollution, 37 days with severe air pollution and 3 days with most severe air pollution.

\section{Association between air pollution and scarlet fever}

After controlling for daily cumulative precipitation, daily mean temperature, daily mean air pressure, seasonality, long-term trends, DOW and public holidays, results from the DLNM showed that the morbidity of scarlet fever was significantly associated with air pollutions, and the lag effects were presented in Table 2. The relative risks (RRs) of air pollution on scarlet fever were only significant at a lag of 7 days, which were 1.172 (95\% CI 1.038-1.323) in mild air pollution, 1.374 (95\% CI 1.078-1.749) in moderate air pollution, 1.610 (95\% CI 1.163-2.314) in severe air pollution and 1.887 (95\% CI 1.163-3.061) in most severe air pollution. Moreover, the cumulative effects of air pollutions on scarlet fever were presented in Fig. 2, and the cumulative RRs at a lag of 0-7 days were 1.454 (95\% CI 1.015-2.082) in mild air pollution, 2.114 (95\% CI 1.031-4.334) in moderate air pollution, 3.073 (95\% CI 1.046-9.023) in severe air pollution and 4.467 (95\% CI 1.062-18.785) in most air pollution.

As shown in Fig. 3, the association between a 10-unit of increase of $\mathrm{PM}_{2.5}$ concentration and the morbidity of scarlet fever was significantly detected from the model (with reference to $75 \mu \mathrm{g} / \mathrm{m}^{3}$ ). The RRs were significant at a lag of $0-2$ and 6 days, with its maximum at a lag of 0 day (1.014, 95\% CI 1.003-1.025), and the cumulative RR at lag 0-7 days was 1.060 (95\% CI 1.039-1.081). However, there was no significant association detected between a 10-unit increase of $\mathrm{O}_{3}$ concentration and morbidity of scarlet fever (with reference to $200 \mu \mathrm{g} / \mathrm{m}^{3}$ ), which was showed in Fig. 4 .

\section{Sensitivity analyses}

Sensitivity analysis was conducted to check whether our coefficient estimates were robust. The effects changed little when changing DF (2-5) for daily cumulative precipitation, daily mean temperature, and daily mean air pressure, and we found that the effects estimated at a lag of 7 days did not change substantially (Additional file 1: Figure S1). Similar effects of air pollutions on scarlet fever were observed when changing DF (6-9 per year) for time (Additional file 1: Figure S2).

\section{Discussion}

Previous studies reveal that scarlet fever is related to meteorological factors [33, 34], however, the potential risk environmental factors have been considered to be more. Our results from DLNM suggested the lagged and cumulative effect of air pollutions on scarlet fever alongside controlling for the potential impact of meteorological factors, day of the week, holiday, seasonality and long-term trend. A viewpoint supported by Liu et al. is also appropriate for our research [35], which is that although this study is based on Qingdao city only, the real impact of scarlet fever due to air pollution might be much greater, given the large population at risk and frequent air pollutions in China. Results from this study might be applicable to most cities in coastal areas of north China, because air quality and climates in those places were similar with that in Qingdao.

Air pollution is the fifth leading global risk factor for public health, which contributes substantially to disease burden [36, 37]. Due to the implementation of policies and plans to reduce the adverse effects of air pollution on public health in China, the air quality at most regions has been improving since 2013 and achieved the decrease of national annual mean concentrations of air pollutants between 2004 and 2018 [13]. However, air pollution remains severe, and its subsequent health effects still persist. In Qingdao, there were 376 days occurring air pollution between 2014 and 2018, accounting for one fifth of this period. During air pollution days, the mean concentrations of pollutants were significantly higher than

Table 2 The RRs of air pollution on the risk of scarlet fever from the DLNM model

\begin{tabular}{lllll}
\hline Lags & Mild & Moderate & Severe & Most severe \\
\hline Lag0 & $1.034(0.912-1.174)$ & $1.071(0.831-1.379)$ & $1.108(0.758-1.619)$ & $1.147(0.691-1.902)$ \\
Lag1 & $1.077(0.994-1.168)$ & $1.161(0.987-1.363)$ & $1.251(0.983-1.592)$ & $1.348(0.977-1.859)$ \\
Lag2 & $1.066(0.980-1.159)$ & $1.137(0.961-1.344)$ & $1.212(0.943-1.558)$ & $1.292(0.924-1.806)$ \\
Lag3 & $1.029(0.957-1.106)$ & $1.058(0.916-1.224)$ & $1.089(0.877-1.353)$ & $1.121(0.839-1.497)$ \\
Lag4 & $0.994(0.925-1.068)$ & $0.988(0.856-1.141)$ & $0.982(0.792-1.219)$ & $0.977(0.732-1.303)$ \\
Lag5 & $0.987(0.908-1.073)$ & $0.974(0.825-1.151)$ & $0.962(0.749-1.235)$ & $0.949(0.680-1.325)$ \\
Lag6 & $1.034(0.954-1.120)$ & $1.069(0.910-1.254)$ & $1.105(0.869-1.405)$ & $1.142(0.829-1.573)$ \\
Lag7 & $1.172(1.038-1.323)^{*}$ & $1.374(1.078-1.749)^{*}$ & $1.610(1.163-2.314)^{*}$ & $1.887(1.163-3.061)^{*}$ \\
\hline
\end{tabular}

Mild mild air pollution, Moderate moderate air pollution, Severe severe air pollution, Most severe most severe air pollution *P $<0.05$ 

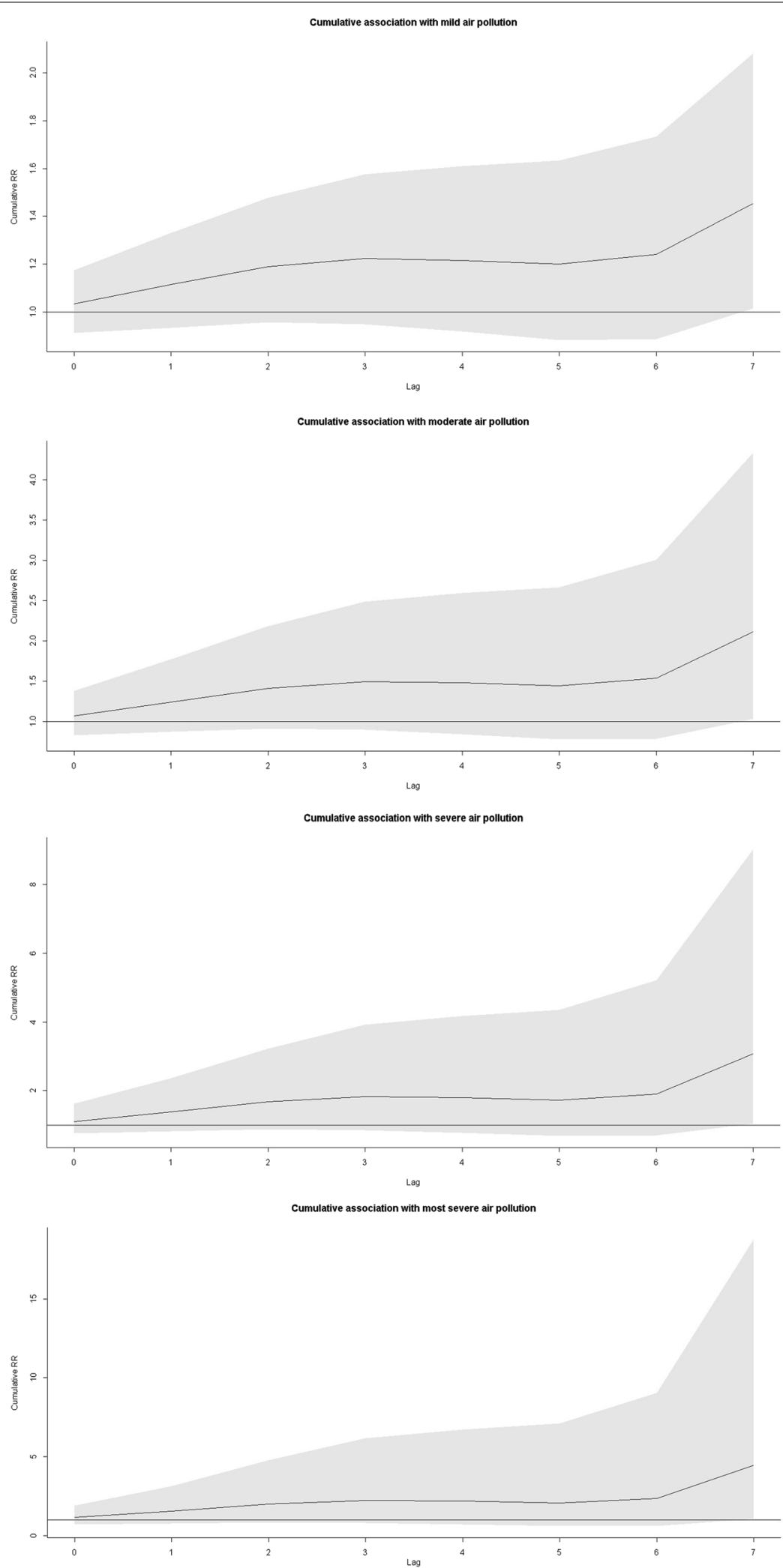

Fig. 2 The cumulative relative risks of different degrees of air pollution at a lag of 0-7 days (including mild pollution, moderate pollution, severe pollution and most severe pollution) 

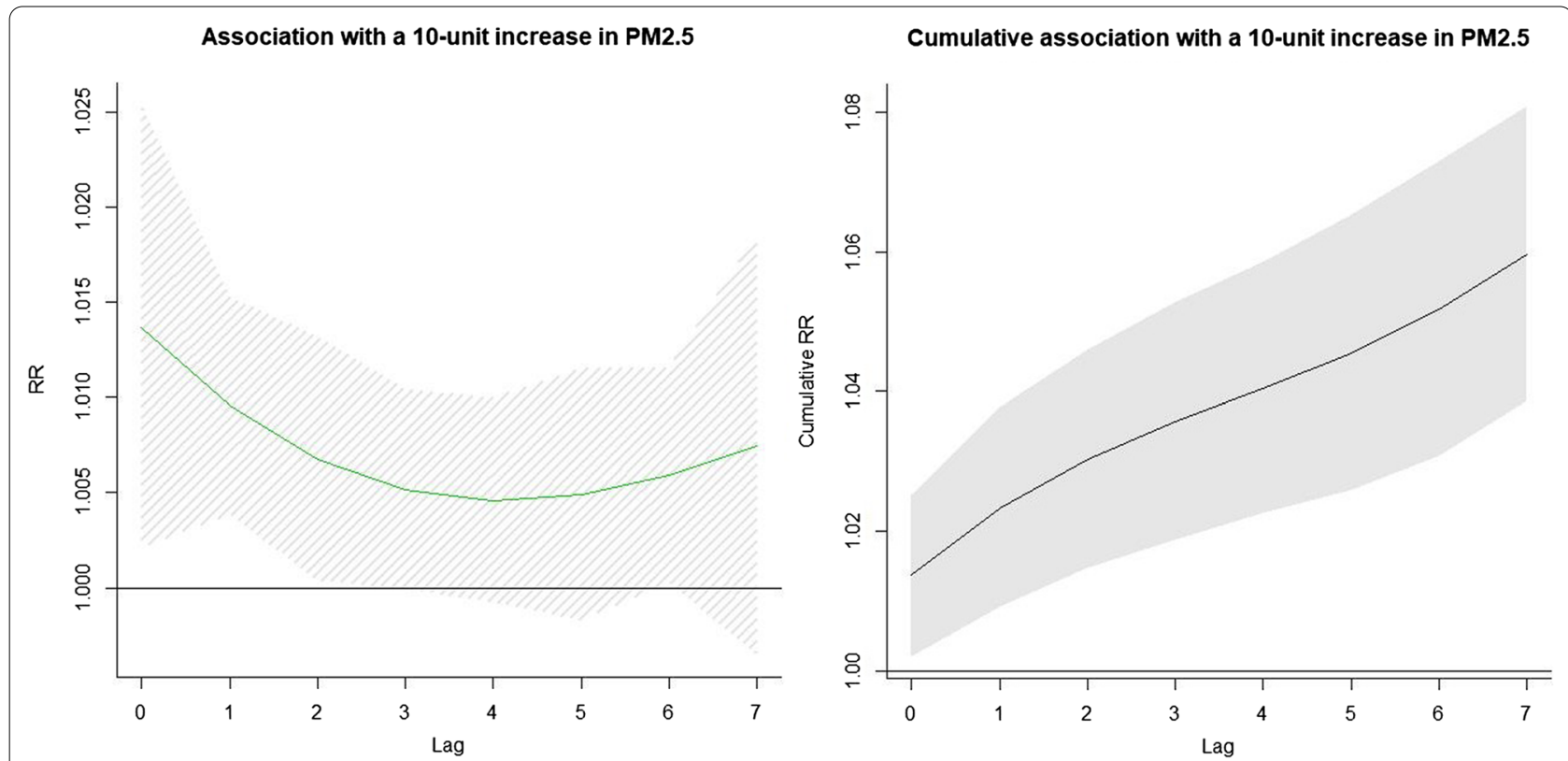

Fig. 3 The relative risks and cumulative relative risks of a 10-unit increase of $\mathrm{PM}_{2.5}$ concentration at a lag of 0-7 days (with reference to standard limit of $75 \mu \mathrm{g} / \mathrm{m}^{3}$ )
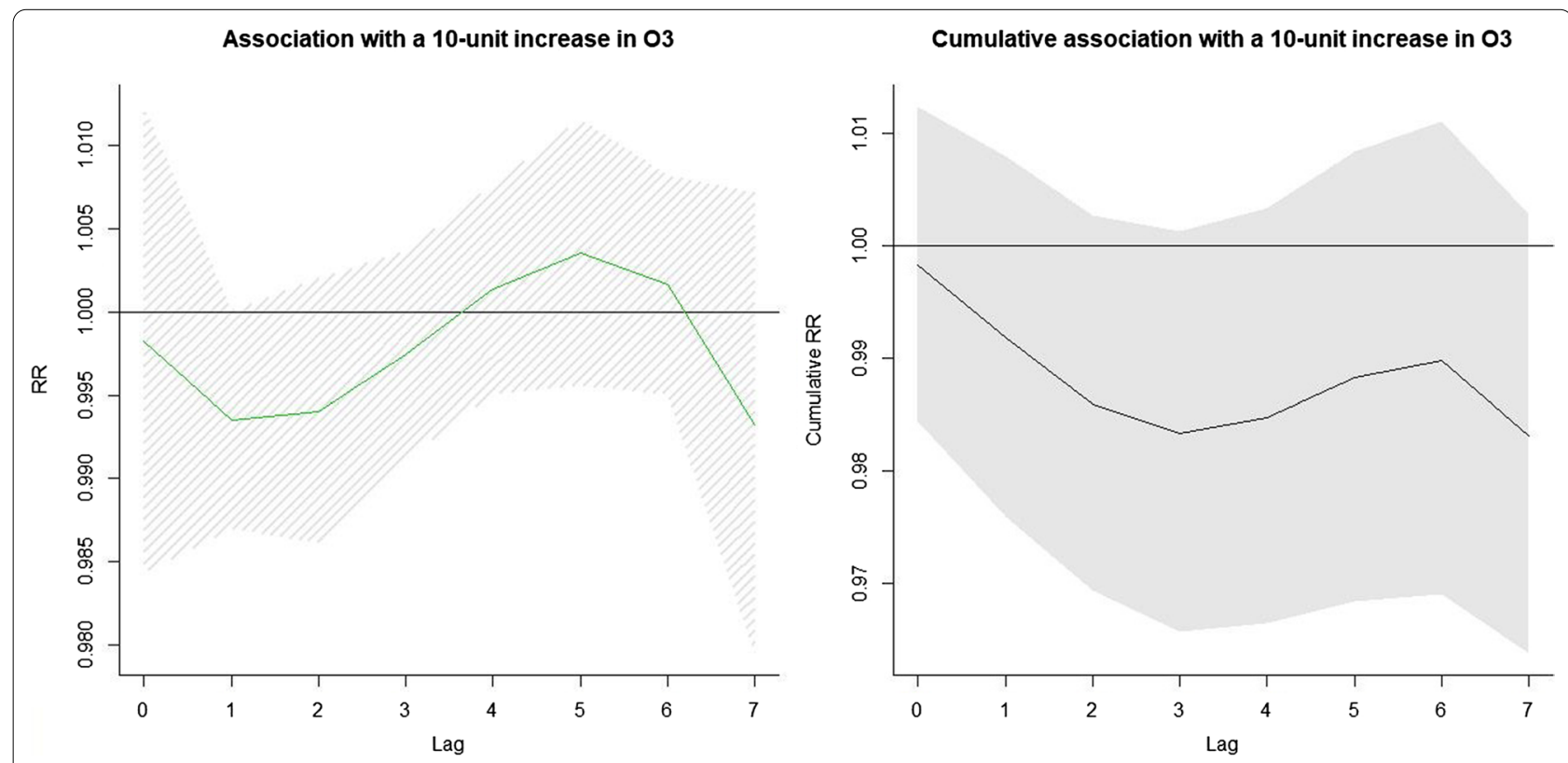

Fig. 4 The relative risks and cumulative relative risks of a 10-unit increase of $\mathrm{O}_{3}$ concentration at a lag of 0-7 days (with reference to standard limit of $200 \mu \mathrm{g} / \mathrm{m}^{3}$ )

non-air pollution days, which increased along with air pollution levels.

To our knowledge, it has been the first time that a study evaluated the risk of air pollution on scarlet fever based on air pollution levels not only pollutant concentrations.
Previous studies mainly focused on the air pollutant concentrations to evaluate the association with diseases $[27,30,33]$. Although using the concentration could appropriately present the impact of air pollutants, it just indicates a single pollutant, which seems to be far from 
adequate for assessing the impact of air pollutions. Air pollution is a complex environmental problem, and it integrates the statuses of various pollutants. Therefore, it should consider integration of various air pollutants at certain moment to analyze the association with diseases. AQI is considered as a summary assessment of ambient air pollutants, aiming at expressing the concentrations of main pollutants on a common scale where effects human health. According to the AQI, air pollution is classified into four levels, including mild pollution, moderate pollution, severe pollution and most severe pollution. Compared with concentrations of air pollutants, the degrees of air pollution might be more interesting in estimating the association between air pollution and scarlet fever, which could present the overall situation of air quality.

In our study, results of the DLNM showed that air pollutions were associated with increased risks of scarlet fever at a lag of 0-7 days. Moreover, it suggested that the risk of air pollutions on scarlet fever could increase along with air pollution levels. Compared with good air quality, the worse air quality may increase the risk of scarlet fever. This could be significant for local government to make advance policies for protecting population health when air pollution is occurring. Additionally, due to the explosion of the child population under the two-child policy in China, the non-vaccine-preventable childhood disease such as scarlet fever might be a potential risk [10, 38], which further increases the exposure population for possible risk of scarlet fever associated with air pollutions. In the recent years of China, the awareness of air pollution and its health implications have been increased significantly, and a series of corresponding measures have been implemented including substantial investments in the improvement of air quality and a multidimensional control strategy aiming at reduce emissions from vehicles and fuels [39-41]. All these actions are very important to decrease the threat of air pollutions merging scarlet fever and other non-vaccine-preventable respiratory infectious diseases in China.

We suppose that the impact of air pollutions on scarlet fever is most depended on the effects of air pollutants. Our results revealed a positive association between daily mean concentration of air pollutant and scarlet fever morbidity, and the cumulative RR of a 10-unit increase of $\mathrm{PM}_{2.5}$ concentration at a lag 0-7 days was significantly evaluated (1.060, 95\% CI 1.039-1.081). However, there was no significant association detected between $\mathrm{O}_{3}$ concentration and scarlet fever. The risk estimate for $\mathrm{PM}_{2.5}$ found in our study was consistent with earlier findings in Beijing [42]. Previous studies tried to investigate the mechanisms of the damage effects of $\mathrm{PM}_{2.5}$, but the biological mechanisms underlying the association between air pollutants and scarlet fever remain elusive. One of the reasons maybe such exposures to elevated concentrations of $\mathrm{PM}_{2.5}$ over short periods may irritate airways in the human respiratory system and potentially increase susceptibility to respiratory infections [43]. Studies suggested that there were three pathways which may promote this possible situation, including injury from free radical peroxidation, imbalanced intracellular calcium homeostasis and inflammatory injury [43]. However, future patient-level and mechanistic research should be done to prove the findings.

Compared with other studies analyzing the association between air pollution and scarlet fever, a significant feature of our study is that we use daily data to detect this association. Different from weekly and monthly data, daily data is more accurate to assess the impact of air pollutions. Appling weekly or monthly data have to face a fact that this would underestimate the effect of extreme pollution events by averaging its impact on a long temporal scale. Using daily data to analyze the association could avoid this situation, and it could identify the degrees of air pollution for more accurate assessment of the impact of air pollution.

Limitations of our study should be acknowledged. Firstly, due to lack of case data, we just evaluated the effect of air pollution on overall population, and cannot analyze the effects among different gender and age groups. Secondly, the effects of many factors, such as population, available health services and hygiene, social and economic status, were not included in this analysis due to unavailable data. Thirdly, we did not analyze the effect of air pollutions on scarlet fever cases by GAS types. In addition, under-reporting is an inevitable issue, which could lead to an underestimation of the impact of air pollutions on scarlet fever.

\section{Conclusion}

In conclusion, air pollution is positively associated with scarlet fever in Qingdao, and the risk of scarlet fever is increased along with the degrees of air pollution. Our findings contribute to developing local strategies to prevent and reduce health impact from scarlet fever and other non-vaccine-preventable respiratory infectious diseases in air polluted areas.

\footnotetext{
Abbreviations

GAS: Group a streptococcus; GAMM: Generalized additive mixed model: DLNM: Distributed lag non-linear model; RR: Relative risk; Cl: Confidence interval; NDSS: Notifiable disease surveillance system; AQI: Air quality index; $|A Q|$ : Individual air quality index; $\mathrm{PM}_{2.5}$ : Particulate matter with a diameter less 2.5 microns; $\mathrm{PM}_{10}$ : Particulate matter with a diameter less 10 microns; $\mathrm{SO}_{2}$ : Sulfur dioxide; $\mathrm{CO}$ : Carbon monoxide; $\mathrm{NO}_{2}$ : Nitrogen dioxide; $\mathrm{O}_{3}$ : Ozone; $\mathrm{DF}$ : Degree of freedom.
} 


\section{Supplementary Information}

The online version contains supplementary material available at https://doi. org/10.1186/s12879-021-06674-8.

\section{Additional file 1: Results of spearman correlation and sensitivity} analysis.

\section{Acknowledgements}

We thank Municipal Centre of Disease Control and Prevention of Qingdao, National Meteorological Information Center of China sharing with us the data needed for this study.

\section{Authors' contributions}

F-CJ, X-WH, TW and WN, conducted the literature review and analyses and drafted the manuscript, and approved the final manuscript as submitted. $\mathrm{Y}$-LH, JJ and BP conducted the data collection, and critically reviewed the manuscript, and approved the final manuscript as submitted. All authors read and approved the final manuscript.

\section{Funding}

This work was supported by the Qingdao Science and Technology Project (Grant No.19-6-1-1-nsh). The funding institution has no role in the design of the study and collection, analysis, and interpretation of data and in writing the manuscript.

\section{Availability of data and materials}

The datasets used during the study are available from the corresponding authors on reasonable request.

\section{Declarations}

\section{Ethics approval and consent to participate}

This study was approved by the Ethics Commission of Qingdao Municipal Center for Disease Control and Prevention (Date: 18 Oct, 2019; Number: QFELL-KY-2019-67), and written informed consent was not applicable. There is no administrative permission required to access the raw data, and the data used in this study was anonymised before its use.

\section{Consent for publication}

Not applicable.

\section{Competing interests}

The authors declare that they have no competing interests.

\section{Author details}

1 Department of Acute Infectious Diseases, Qingdao Municipal Center for Disease Control and Prevention, Qingdao Institute of Prevention Medicine, Qingdao City, Shandong Province, People's Republic of China. ${ }^{2}$ Qingdao Women and Children's Hospital, Qingdao University, No.6 Tongfu Road, Qingdao City 266000, Shandong Province, People's Republic of China.

\section{Received: 17 November 2019 Accepted: 8 September 2021}

Published online: 21 September 2021

\section{References}

1. Lamagni T, Guy R, Chand M, Henderson KL, Chalker V, Lewis J, Saliba V, Elliot AJ, Smith GE, Rushton S, et al. Resurgence of scarlet fever in England, 2014-16: a population-based surveillance study. Lancet Infect Dis. 2017;18(2):180-7.

2. Mandell GL, Bennett JE, Dolin R. Mandell, Douglas and Bennett's Principles and Practice of Infectious Diseases, 7th Edition. Churchill Livingstone 2009

3. Andrey DO, Posfay-Barbe KM. Re-emergence of scarlet fever: old players return? Expert Rev Anti Infect Ther. 2016;14:687-9.

4. Lee CF, Cowling BJ, Lau EHY. Epidemiology of reemerging scarlet fever, Hong Kong, 2005-2015. Emerg Infect Dis. 2017;23(10):1707-10.
5. Basetti S, Hodgson J, Rawson TM, Majeed A. Scarlet fever: a guide for general practitioners. London J Prim Care. 2017;9(5):1-3.

6. Hsieh YC, Huang YC. Scarlet fever outbreak in Hong Kong, 2011. J Microbiol Immunol Infect. 2011;44:409-11.

7. Park DW, Kim SH, Park JW, Kim MJ, Cho SJ, Park HJ, Jung SH, Seo MH, Lee YS, Kim BH, et al. Incidence and characteristics of scarlet fever, South Korea, 2008-2015. Emerg Infect Dis. 2017:23(4):658-61.

8. Guy R, Williams C, Irvine N, Reynolds A, Coelho J, Saliba V, Thomas D, Doherty L, Chalker V, von Wissmann B, et al. Increase in scarlet fever notifications in the United Kingdom, 2013/2014. Euro Surveill. 2014;19(12):20749.

9. Lamagni T, Guy R, Chand M, Henderson KL, Chalker V, Lewis J, Saliba V, Elliot AJ, Smith GE, Rushton S, et al. Resurgence of scarlet fever in England, 2014-16: a population-based surveillance study. Lancet Infect Dis. 2018;18(2):180-7

10. Liu Y, Chan TC, Yap LW, Luo Y, Xu W, Qin S, Zhao N, Yu Z, Geng X, Liu SL. Resurgence of scarlet fever in China: a 13-year population-based surveillance study. Lancet Infect Dis. 2018;18(8):903-12.

11. Mahara G, Chhetri JK, Guo X. Increasing prevalence of scarlet fever in China. BMJ. 2016:353:i2689.

12. Xu P, Chen Y, Ye X. Haze, air pollution, and health in China. Lancet. 2013;382(9910):2067.

13. Chen Z, Wang JN, Ma GX, Zhang YS. China tackles the health effects of air pollution. Lancet. 2013;382(9909):1959-60.

14. Chan CK, Yao X. Air pollution in megacities in China. Atmos Environ. 2008;42(1):1-42.

15. Wang S, Hao J. Air quality management in China: issues, challenges, and options. J Environ Sci. 2012;24(1):2-13.

16. Kan $\mathrm{H}$, Chen $\mathrm{R}$, Tong $\mathrm{S}$. Ambient air pollution, climate change, and population health in China. Environ Int. 2012;42:10-9.

17. Wang HJ, Chen HP, Liu J. Arctic sea ice decline intensified haze pollution in eastern China. Atmos Oceanic Sci Lett. 2015;8(1):1-9.

18. Zou JH, Xu FX, Zou B, Li SX, Yang ZL. Spatial-temporal characteristics of haze in the key tourism cities of China [in Chinese]. Trop Geogr. 2018;38(3):143-50.

19. Li JX, Wang PC, Gang F. The relationship between the incidence of scarlet fever and meteorological factors in Shandong province [in Chinese]. Chin Prevent Med. 2011:12(1):149-51.

20. Rao HX, Li DM, Zhao XY, Yu J. Spatiotemporal clustering and meteorological factors affected scarlet fever incidence in mainland China from 2004 to 2017. Sci Total Environ. 2021;777:146145.

21. Ministry of Health of the People's Republic of China. Diagnostic criteria for scarlet fever. China: Beijing, 2008:1-4.

22. Pan S, Ni W, Li W, Li G, Xing Q. Effects of PM2.5 and PM10 on congenital hypothyroidism in Qingdao, China, 2014-2017: a quantitative analysis. Ther Adv Endocrinol Metab. 2019;10:2042018819892151.

23. Gasparrini A, Armstrong B, Kenward MG. Distributed lag non-linear models. Stat Med. 2010;29(21):2224-34.

24. Ding Z, Guo P, Xie F, Chu H, Li K, Pu J, Pang S, Dong H, Liu Y, Pi F, et al. Impact of diurnal temperature range on mortality in a high plateau area in southwest China: a time series analysis. Sci Total Environ. 2015;526:358-65.

25. Zhang Y, Ni H, Bai L, Cheng Q, Zhang H, Wang S, Xie M, Zhao D, Su H. The short-term association between air pollution and childhood asthma hospital admissions in urban areas of Hefei City in China: a time-series study. Environ Res. 2019;169:510-6.

26. Chen K, Glonek G, Hansen A, Williams S, Tuke L, Salter A, Bi P. The effects of air pollution on asthma hospital admissions in Adelaide, South Australia, 2003-2013: time-series and case-crossover analyses. Clin Exp Allergy. 2016:46(11):1416-30.

27. Lam HC, Li AM, Chan EY, Goggin WB. The short-term association between asthma hospitalisations, ambient temperature, other meteorological factors and air pollutants in Hong Kong: a time-series study. Thorax. 2016:71(12):1097-109.

28. Chen R, Chu C, Tan J, Cao J, Song W, Xu X, Jiang C, Ma W, Yang C, Chen B, et al. Ambient air pollution and hospital admission in Shanghai, China. J Hazard Mater. 2010;181:234-40

29. Chen F, Deng Z, Deng Y, Qiao Z, Lan L, Meng Q, Luo B, Zhang W, Ji K, Qiao $X$, et al. Attributable risk of ambient PM10 on daily mortality and years of life lost in Chengdu, China. Sci Total Environ. 2017:581-582:426-33. 
30. Lamden $\mathrm{KH}$. An outbreak of scarlet fever in a primary school. Arch Dis Child. 2011;96(4):394-7.

31. Danesh Yazdi M, Wang Y, Di Q, Zanobetti A, Schwartz J. Long-term exposure to PM2.5 and ozone and hospital admissions of Medicare participants in the Southeast USA. Environ Int. 2019;130:104879.

32. Lei R, Zhu F, Cheng H, Liu J, Shen C, Zhang C, Xu Y, Xiao C, Li X, Zhang J, et al. Short-term effect of PM2.5/O3 on non-accidental and respiratory deaths in highly polluted area of China. Atmos Pollut Res. 2019;5:1412-9.

33. Duan $Y$, Yang $L J$, Zhang YJ, Huang XL, Pan GX, Wang J. Effects of meteorological factors on incidence of scarlet fever during different periods in different districts of China. Sci Total Environ. 2017;581-582:19-24.

34. Duan Y, Huang XL, Wang YJ, et al. Impact of meteorological changes on the incidence of scarlet fever in Hefei City. China Int J Biometeorol. 2016;60(10):1543-50.

35. Liu ZD, Li J, Zhang Y, Ding GY, Xu X, Gao L, Liu XN, Liu QY, Jiang BF. Distributed lag effects and vulnerable groups of floods on bacillary dysentery in Huaihua. China Sci Rep. 2016;6:29456.

36. Wang Q, Wang J, Zhou J, Ban J, Li T. Estimation of PM2.5-associated disease burden in China in 2020 and 2030 using population and air quality scenarios: a modelling study. Lancet Planet Health. 2019:3(2):e71-80.

37. Cohen AJ, Brauer M, Burnett R, Anderson HR, Frostad J, Estep K, Balakrishnan K, Brunekreef B, Dandona L, Dandona R, et al. Estimates and 25-year trends of the global burden of disease attributable to ambient air pollution: an analysis of data from the Global Burden of Diseases Study 2015. Lancet. 2017;389(10082):1907-18.
38. Zeng Y, Hesketh T. The effects of China's universal two-child policy. Lancet. 2016;388(10054):1930-8.

39. Zhu G, Hu W, Liu Y, Cao J, Ma Z, Deng Y, Sabel CE, Wang H. Health burdens of ambient PM2.5 pollution across Chinese cities during 2006-2015. J Environ Manage. 2019;243:250-6.

40. Achakulwisut P, Brauer M, Hystad P, Anenberg SC. Global, national, and urban burdens of paediatric asthma incidence attributable to ambient NO2 pollution: estimates from global datasets. Lancet Planet Health. 2019;3(4):e166-78

41. Greenbaum D. Making measurable progress in improving China's air and health. Lancet Planet Health. 2018;2(7):e289-90.

42. Mahara G, Wang C, Yang K, Chen S, Guo J, Gao Q, Wang W, Wang Q, Guo $X$. The association between environmental factors and scarlet fever incidence in Beijing region: using GIS and spatial regression models. Int J Env Res Pub He. 2016;13(11):1083-98.

43. Yufei X, Yuehua X, Minhua S, Yixin L. The impact of PM2.5 on the human respiratory system. J Thorac Dis. 2016;8(1):E69-74.

\section{Publisher's Note}

Springer Nature remains neutral with regard to jurisdictional claims in published maps and institutional affiliations.
Ready to submit your research? Choose BMC and benefit from:

- fast, convenient online submission

- thorough peer review by experienced researchers in your field

- rapid publication on acceptance

- support for research data, including large and complex data types

- gold Open Access which fosters wider collaboration and increased citations

- maximum visibility for your research: over 100M website views per year

At BMC, research is always in progress.

Learn more biomedcentral.com/submissions 